\title{
Die Erde ist doch eine Scheibe!
}

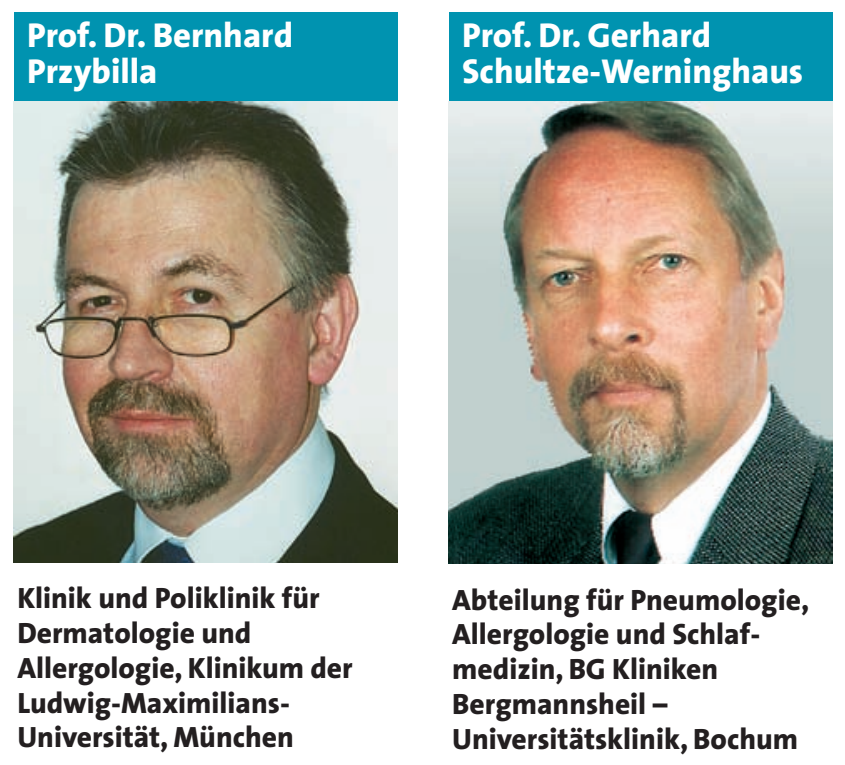

profund Vertraute manipuliert werden? Während die medizinische Wissenschaft in hoch komplexen Abläufen gesichertes Wissen destilliert und diese Essenz in Leitlinien oder Positionspapieren niederlegt (zum "Heuschnupfen" siehe Allergo J 2003; 12: 182-94), greift die Verfasserin des Zeitungsartikels eine andere, durch nichts als bestenfalls "Meinung“ gestützte Vorgehensweise auf und stellt sie geschickt als mindestens gleichwertig dar. Wissen einerseits und Meinung des behauptenden stand nur (?) Folgendes: Gegen Heuschnupfen „greifen Münchner Ärzte von der Internationalen Fachgesellschaft für chinesiche Medizin (Telefon 388880 31) zu Nadeln und Kräutern. Der Internist Josef H... zeigte sich selber überrascht vom großen Erfolg einer Behandlung mit Akupunktur und chinesischen
„Wissen und Unwissen sind in unserer Mediengesellschaft gleichberechtigt geworden: Wahrheit oder blubbernde Sprechblasen - gleich gültig."
Nachteil: „Die gesetzlichen Kassen bezahlen nicht ..." Den IGeL-Erbringer wird's nur freuen!

Auf jeden Fall ist zu einer Wirksamkeitsquote von $80 \% \mathrm{zu}$ gratulieren, Linksunterzeichneter hat es - bei einer anderen "Volkskrankheit" in einer randomisierten, doppelblinden, plazebokontrollierten Studie (Allergo J Tees. Eine Praxis-Studie mit 60 Heuschnupfen-Patienten führte bei etwa $80 \%$ von ihnen zu einer Besserung der Symptome."

Nun wissen also wir und die Leser der Süddeutschen Zeitung, wie man Heuschnupfen fortschrittlich behandelt. Denn die Therapie des Wahlchinesen Josef H. wird von der „berichtenden" Journalistin kontrapunktisch an das Ende ihres vierspaltigen Beitrages „Harte Zeiten für Allergiker“ gestellt vorher durften zwei „Uni-Mediziner die klassischen Methoden hochhalten“. Die sprachen von so öden Therapien wie „so genannten Antihistaminika“, „Vorsichtsmaßnahmen“, „Tabletten und Sprays“ oder „Hyposensibilisierung“. Das kann's doch nicht gewesen sein!? Natürlich nicht! Allerdings, auch bei der chinesischen Medizin gibt es einen 1998; 7: 261-3) - bisher nur auf $74,3 \%$ heilsame Plazebowirkung gebracht. $\mathrm{Zu}$ hoffen ist, dass die PraxisStudie nach GCP-Kriterien verlief und die Patienten über die Behandlung und andere Möglichkeiten der Therapien ausdrücklich aufgeklärt wurden.

Warum tun Journalisten so etwas? Natürlich muss in einer Zeitung etwas mehr oder weniger "Sensationelles“ stehen, damit die Leser dabei bleiben aber darf der mit einem Thema nicht

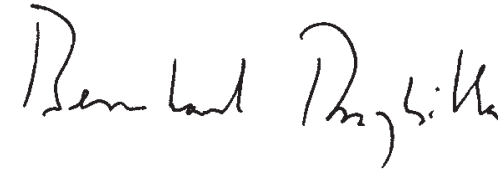

Prof. Dr. B. Przybilla
Unwissenden andererseits sind in unserer Mediengesellschaft gleichberechtigt geworden: Wahrheiten oder blubbernde Sprechblasen - gleich gültig. Diese pseudotolerante, letztlich aber narzisstisch arrogante und den Geist tötende Wurschtigkeit schadet nicht nur den Allergiekranken, sondern gesellschaftsweit allen.

Allergo Journal jedenfalls wird weiter Wissen vermitteln. Über die Zusammenhänge zwischen örtlicher und systemischer allergologischer Entzündungsreaktion lesen Sie auf Seite 388, im Blickpunkt stehen die Mimotope, eine viel versprechende Entwicklung der molekularen Allergologie (Seite 382). Und die Abstracts des 19. Fortbildungskongresses in Davos (Seite 367) lassen die ganze Vielfalt aktueller allergologischer Forschung erkennen.

Mit den besten Grüßen

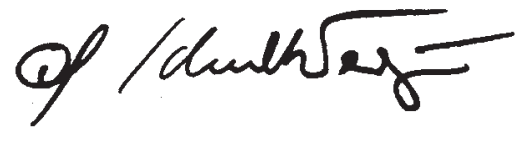

Prof. Dr. G. Schultze-Werninghaus 